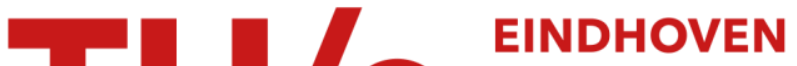 UNIVERSITY OF TECHNOLOGY
}

\section{Subcritical crack growth in MnZn Ferrites with a Bimodal defect distribution}

\section{Citation for published version (APA):}

Donners, M. A. H., Dortmans, L. J. M. G., With, de, G., \& Graaf, de, M. J. M. (1997). Subcritical crack growth in MnZn Ferrites with a Bimodal defect distribution. Journal of the European Ceramic Society, 17(13), 1591-1596. https://doi.org/10.1016/S0955-2219(97)00013-7

DOI:

10.1016/S0955-2219(97)00013-7

Document status and date:

Published: 01/01/1997

\section{Document Version:}

Publisher's PDF, also known as Version of Record (includes final page, issue and volume numbers)

\section{Please check the document version of this publication:}

- A submitted manuscript is the version of the article upon submission and before peer-review. There can be important differences between the submitted version and the official published version of record. People interested in the research are advised to contact the author for the final version of the publication, or visit the $\mathrm{DOI}$ to the publisher's website.

- The final author version and the galley proof are versions of the publication after peer review.

- The final published version features the final layout of the paper including the volume, issue and page numbers.

Link to publication

\section{General rights}

Copyright and moral rights for the publications made accessible in the public portal are retained by the authors and/or other copyright owners and it is a condition of accessing publications that users recognise and abide by the legal requirements associated with these rights.

- Users may download and print one copy of any publication from the public portal for the purpose of private study or research.

- You may not further distribute the material or use it for any profit-making activity or commercial gain

- You may freely distribute the URL identifying the publication in the public portal.

If the publication is distributed under the terms of Article 25fa of the Dutch Copyright Act, indicated by the "Taverne" license above, please follow below link for the End User Agreement:

www.tue.nl/taverne

Take down policy

If you believe that this document breaches copyright please contact us at:

openaccess@tue.nl

providing details and we will investigate your claim. 


\title{
Subcritical Crack Growth in MnZn Ferrites with a Bimodal Defect Distribution
}

\author{
M. Donners, ${ }^{a}$ L. Dortmans, ${ }^{a}$ G. de With ${ }^{a} \&$ M. de Graaf ${ }^{b}$ \\ ${ }^{a}$ Centre for Technical Ceramics, PO Box 595, 5600 AN Eindhoven, The Netherlands \\ ${ }^{b}$ Philips Components, BG Magnetic Products, PO Box 218, 5600 MD Eindhoven, The Netherlands
}

(Received 8 February 1996; revised version received 20 December 1996; accepted 3 January 1997)

\begin{abstract}
The mechanical strength and suhcritical crack growth (SCG) behaviour of four types of $\mathrm{MnZn}$ ferrite $E$ cores were determined using constant stress rate tests. Decreasing the stress rate or introducing water decreases the mechanical strength. Using fractography it was shown that the mechanical strength of the standard type of cores depends on the behaviour of two kinds of defect: large grains and pores surrounding agglomerates, having a different SCG susceptibility. Therefore a bimodal strength distribution was used to give a statistical description of these data. Eliminating the large grains by adapting the processing results in cores with only the pores surrounding agglomerates as critical defect. The strength distributions of these cores are comparable to those of the original that have failed on this type of defect. Removing both defect types, besides improving strength, also reduces the susceptibility to subcritical crack growth. (C) 1997 Elsevier Science Limited.
\end{abstract}

\section{Introduction}

The mechanical reliability of $\mathrm{MnZn}$ ferrite cores is becoming more and more important. Reasons for this are the trend towards higher power throughput, ongoing miniaturization of electronic components and the use of modern printed circuit board soldering methods. ${ }^{1,2}$ All these factors lead to higher thermo-mechanical loads and thus to a need to better understand the factors determining the mechanical behaviour of these materials.

\subsection{The mechanical behaviour of $\mathrm{MnZn}$ ferrites}

The object of this work was to give a first characterization of the subcritical crack growth (SCG) behaviour of a typical MnZn ferrite as used in power applications and to find the defects limiting its strength, by applying fractography and fracture statistics systematically.

The mechanical strength of MnZn ferrites has been shown to depend to a large extent on the oxidation state. ${ }^{3-6}$ The mechanical integrity of ferrites is also known to be affected by $\mathrm{SCG}^{7-9}$ (see for a general discussion of SCG, e.g. Refs 10 and 11). The SCG behaviour of a material is best characterized using a so-called $v-K$ curve. ${ }^{10,11}$ In such a plot of crack growth rate versus stress intensity, three regimes can be distinguished. In region $I$, crack growth rate is limited by the rate of the physical or chemical interaction of the 'aggressive agent' with the material at the crack tip. In region II, the supply of 'aggressive agent' from the environment to the crack tip becomes rate-limiting. At even higher stress intensities, in region III, the crack accelerates to its final speed. In most cases, region $I$ is the most important. Assuming that there is no threshold stress intensity to SCG, Charles introduced a power law to describe the crack growth velocity in region $\mathrm{I}$, as a function of mode I stress intensity $K_{\mathrm{I}} \cdot{ }^{12}$

$$
v=A K_{\mathrm{I}}^{n}
$$

The exponent $n$ is nowadays widely used as a quantitative measure of the susceptibility to SCG. By integrating the power law, one can find a relation between the inert strength $S_{\mathrm{f}}$, the constant stress rate $\partial \sigma / \partial t$ and actual strength $\sigma_{\mathrm{f}}$ :

$$
S_{\mathrm{f}}^{n-2}=\sigma_{\mathrm{f}}^{n-2}+\frac{B}{(\partial \sigma / \partial t)} \sigma_{\mathrm{f}}^{n+1}
$$

using a constant $B$, incorporating the constants $A$ and $n$, the critical stress intensity $K_{\mathrm{Ic}}$, and the geometry factor $Y$ from the definition of the stress intensity. Here the inert strength is the strength not influenced by SCG, as found by measuring in an inert environment or at high stress rates. This equation can be used to determine the value of $n$ and $A$ from strength data. 


\subsection{Bimodal defect distributions}

The probability of failure $P_{\mathrm{f}, 1+2}$ of a sample containing two independent, concurrent defect distributions 1 and 2 , is given by: ${ }^{13}$

$$
P_{\mathrm{f}, 1+2}=1-\left(1-P_{\mathrm{f}, 1}\right)\left(1-P_{\mathrm{f}, 2}\right)
$$

using the failure probabilities $P_{\mathrm{f}, 1}$ and $P_{\mathrm{f}, 2}$ of samples having only the respective defect distribution. The failure probability of a single defect population under an applied stress $\sigma$ can be described using the Weibull equation. Introducing this equation for both defect types, results in: ${ }^{13-15}$

$$
P_{\mathrm{f}}=1-\exp \left(-\left(\frac{\sigma}{S_{1}}\right)^{m_{1}}-\left(\frac{\sigma}{S_{2}}\right)^{m_{2}}\right)
$$

To obtain the characteristic strength parameters $S_{\mathrm{i}}$ and the Weibull moduli $m_{\mathrm{i}}$ corresponding to the two defect populations, the strength data of both have to be treated separately. Based on the observations made by fractography, one can split up the complete data set in two separate sets, one for each defect type. To give a correct statistical description of these sets, the estimated failure probability has to be corrected, using a procedure known as censoring. ${ }^{14}$ In the 'standard' analysis of monomodal distributed defects, the failure probability of each sample is estimated using the rank order number $i$ of the samples sorted on strength. The rank order numbers have to be equidistantly spaced from zero to the total number of samples in the set (the increment between successive rank order numbers is constant). If one or several samples are removed from a set (e.g. when they failed on a specific type of defect) the increment between the rank order numbers, now called mean order numbers, of the remaining samples has to be increased to: ${ }^{14}$

$$
\Delta \mathrm{i}=\frac{(N+1)-[\text { previous mean order number }]}{1+[\text { number of items beyond present removed set }]}
$$

Using this routine, a separate set for one of the defect types can be obtained by removing the samples failed on the other defect type from the complete set of data, using fractographical observation.

\section{Experimental}

To determine the mechanical strength and (SCG) behaviour of typical soft ferrite components, mechanical tests were performed on $\mathrm{MnZn}$ ferrite E 42 cores. The cores were all subjected to $\mathrm{W}$ tests. ${ }^{1}$ In this test the largest tensile stresses are found in two regions on the back of the core, as indicated in Fig. 1. The relation between applied force and tensile stress level was determined using

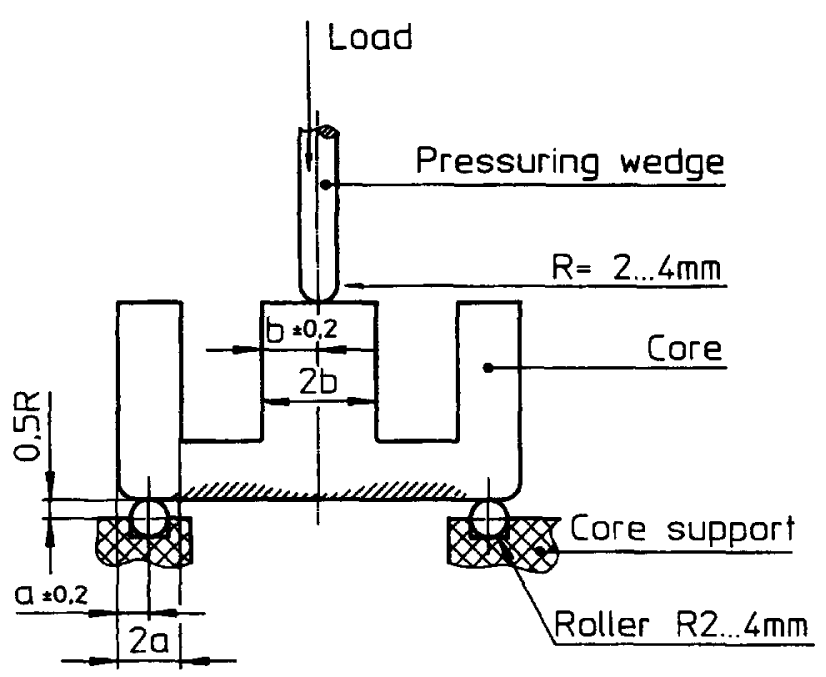

Fig. 1. $\mathrm{E}$ core in $\mathrm{W}$ test; shading indicates region of highest tensile stresses (for an E 42 core, $a=3.1 \mathrm{~mm}, b=6.1 \mathrm{~mm}$ ).

finite element calculations based on isotropic linear elastic behaviour. The cores were tested with a constant stress rate (CSR tests) on a universal testing machine with calibrated stress rates, recording the fracture force. Prior to the tests, the edges of the backs of the cores were chamfered on a wetted P400 sandpaper disc, to exclude the possibility of fracture originating from the edges. All cores were subsequently dried.

The humidity of the testing atmosphere was decreased by flushing a Perspex chamber, surrounding the test set-up, with dry nitrogen gas until the dew-point temperature was lowered to $-25^{\circ} \mathrm{C}$, equivalent to a relative humidity of $2.5 \%$ ('dry' tests). The humidity was measured using an electronic moisture sensor, fitted in the chamber wall. Alternatively, the back of the core was entirely in contact with tap water ('wet' tests).

Fractography was applied to all broken cores. After finding the location of the critical defect on the fracture surface with the unaided eye, a SEM was used to establish its nature.

\section{Results and discussion}

\subsection{Strength and defects of standard cores}

A standard batch of $\mathrm{E}$ cores was made, using a normal industrial processing route. The cores of this standard batch were designated 'type A'. In CSR tests, the strength $\sigma_{\mathrm{f}}$ of these cores decreases when decreasing stress rate $\partial \sigma / \partial t$, as shown in Fig. 2, showing a decrease of about $30 \%$ (comparing the strength as found at the highest and lowest stress rates) in dry tests. The presence of water increases this effect, resulting in a strength decrease of about $45 \%$. The range of stress rates was too small to give a reliable estimate of the value of the SCG parameters $n$ and $A$. 


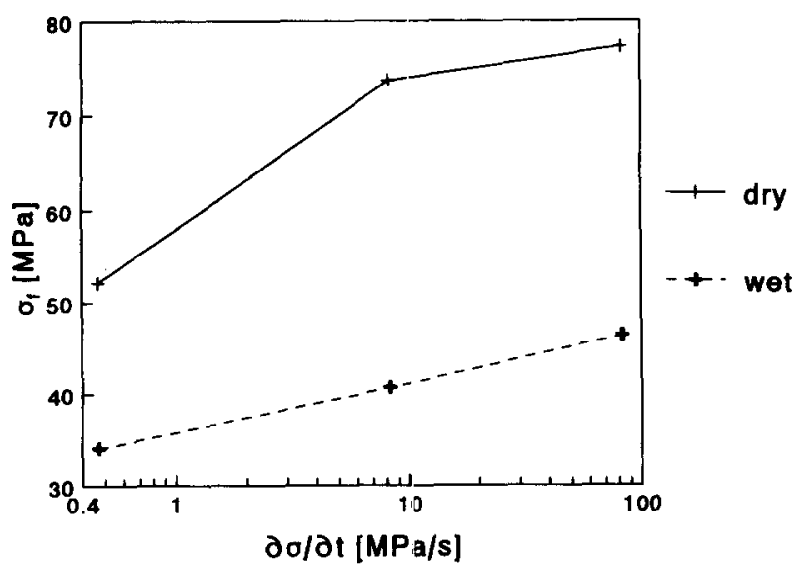

Fig. 2. Mechanical strength of standard (type 'A') cores versus stress rate (normal markers inclicate dry tests, bold markers indicate wet tests).

Using fractography, it was shown that the crack growth leading to failure of cores of type A initiates on microstructural surface defects of one of two types. The first type consists of excessively grown grains, labelled ' $\mathrm{g}$ ' (Fig. 3). These defects can originate from chemical interaction of the ferrite with the alumina refractory powder, on which the cores are placed on their back during firing. Zinc loss, promoted by the formation of $\mathrm{ZnAl}_{2} \mathrm{O}_{4}$ with the alumina refractory, gives rise to residual stresses, local disturbances in the redox equilibrium and an increase in grain boundary energy of the ferrite. The latter would promote excessive grain growth, ${ }^{16,17}$ as this decreases the surface-to-volume ratio of the grains. The second type of defect consists of large pores surrounding insufficiently bonded agglomerates, labelled ' $a$ ' (Fig. 4). Possible causes could be a different elastic relaxation after pressing or a faster densification due to a higher density of these agglomerates relative to the neighbouring agglomerates. ${ }^{18}$

In testing at low stress rates the majority of failures initiate on defects of type ' $g$ '. With increasing

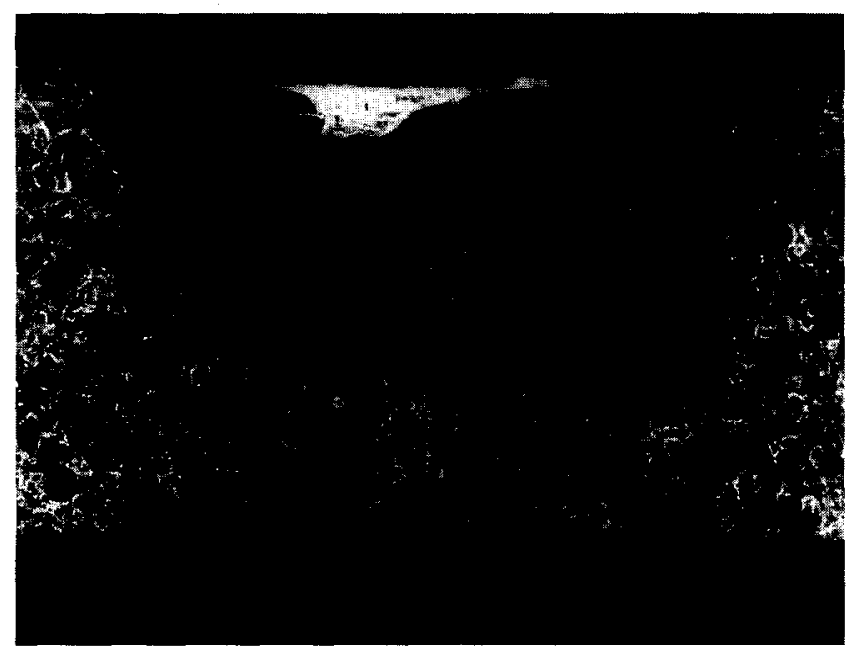

Fig. 3. Defect of type 'g': excessively large grown grain; SEM photograph, white bar indicates $100 \mu \mathrm{m}$, view on fracture surface with the tensile surface on top.

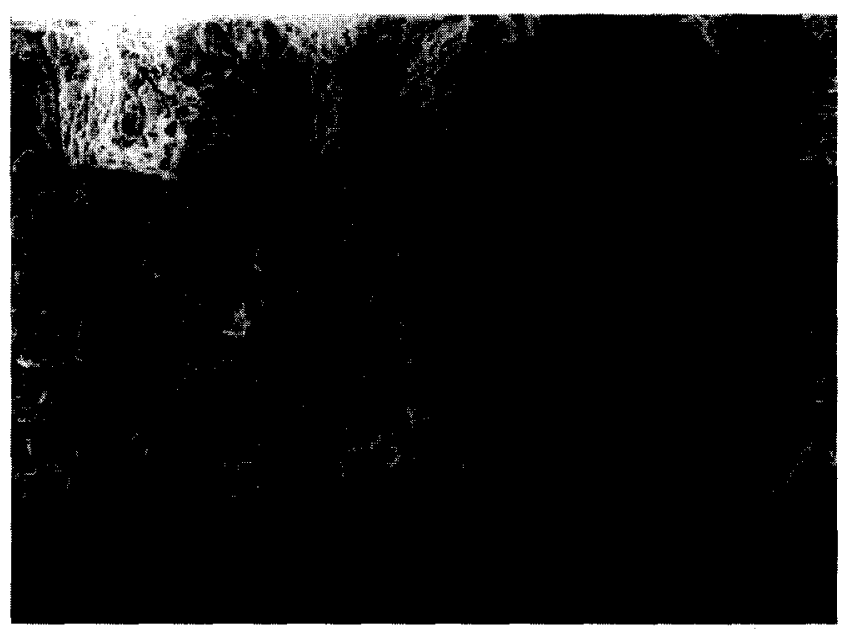

Fig. 4. Defect of type 'a': pores around insufficiently bonded agglomerates: SEM photograph, white bar indicates $100 \mu \mathrm{m}$, view on fracture surface with the tensile surface on top.

stress rate an increasing number of failures starts at defects of the other kind (Fig. 5). Introducing water increases the percentage of cores failing on defect ' $g$ '. Figure 6 shows the mean strengths of both the complete dry and wet tests, as well as the mean strengths of the cores broken either at defects ' $g$ ' or at defects of type ' $a$ '. In wet tests,

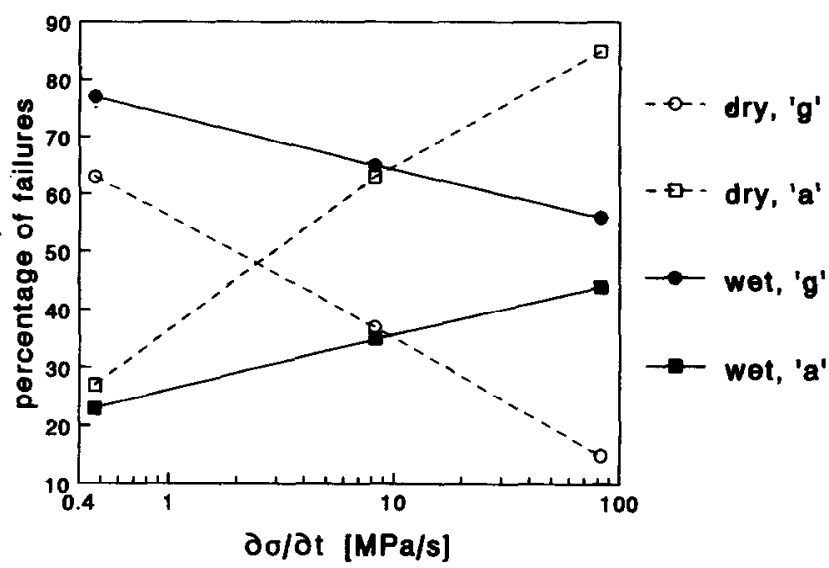

Fig. 5. Fraction of failures on each kind of defect, depending on stress rate and humidity.

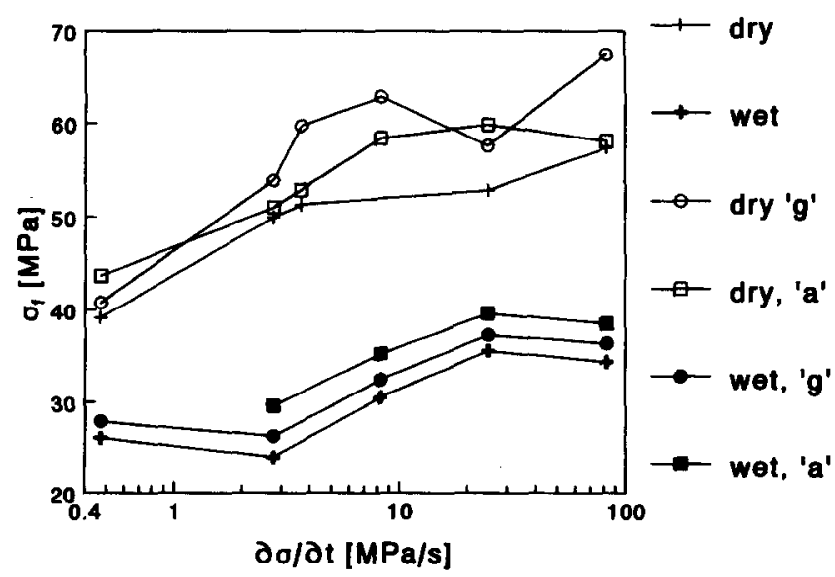

Fig. 6. Mean strength of cores of type $A$, both complete sets and sets censored on critical defect, versus stress rate (normal markers indicate dry tests, bold markers indicate wet tests). 
the cores broken on defect ' $a$ ' always show the highest mean strength and the relative differences in strength are about equal at all stress rates. In dry tests, cores having failed on defects of type ' $g$ ' have a higher mean strength (except for the lowest stress rate) and the difference seems to increase with increasing stress rate. In order to have a representative number of cores broken on each kind of defect, even with small failure fractions, all tests shown in Fig. 5 were performed on a total of 75 cores each. All other tests were made on 25 cores.

Figure 7 shows the Weibull plots of both the complete and the censored sets of a single test. Introducing a second kind of defect in cores containing previously only one kind of defect decreases the strength of these cores. If censoring were not applied, then the curve resulting from the combined effect of the two kinds of defect would be located somewhere between the two 'monomodal' curves. Note that Fig. 7, as all Weibull plots of bimodal distributions found in this study, does not show the knee in the plot of the complete set, whose presence is often associated with the existence of a bimodal distribution, even without fractographical evidence. ${ }^{19}$

The higher susceptibility to SCG of cores failing on defect ' $g$ ', relative to failures on defect ' $a$ ', could be linked to the chemical changes in the ferrite associated with zinc loss. This suggests that the oxidation degree of the ferrite, changed by zinc loss, not only determines strength, but also could influence the sensitivity to subcritical crack growth.
3.2 Strength and defects after eliminating defect ' $g$ ' As was mentioned earlier, the defects of type ' $\mathrm{g}$ ' originate from a chemical reaction of the ferrite with alumina refractory material. To eliminate these defects, cores were fired, standing 'legs down' on similar $E$ cores resting on their backs. These cores were designated 'type B'. In this way, contact with the alumina refractory was prevented while still allowing for movement of the core due to shrinkage. The mean strength of type B cores in dry tests at the intermediate stress rate is about equal to that of type A cores. In wet tests, however, type B cores give a $15 \%$ higher strength compared to type A cores. Fractography shows that type B cores only fail at defects of type ' $a$ '. A Weibull plot of the results of dry and wet tests of type B and type A cores, the latter censored to remove defect ' $\mathrm{g}$ ', is shown in Fig. 8. In this example, the mean strength in wet tests of type $B$ cores is about equal to that of type $A$ cores having failed on defect ' $a$ '. In dry tests, type $B$ cores are about $10 \%$ less strong. In both dry and wet tests, type B cores show a higher Weibull modulus (14, as compared to 8 for wet and 6 for dry tests of type A 'a' cores). This again shows that cores failing on defects of type ' $a$ ' are less susceptible to SCG.

\subsection{Strength and defects after grinding of tensile surface}

Both defects ' $a$ ' and ' $g$ ' appear exclusively on the outer surface of the cores. Both have a characteristic size of about 100 to $200 \mu \mathrm{m}$. Grinding $0.2 \mathrm{~mm}$ off the back of the cores, should eliminate both

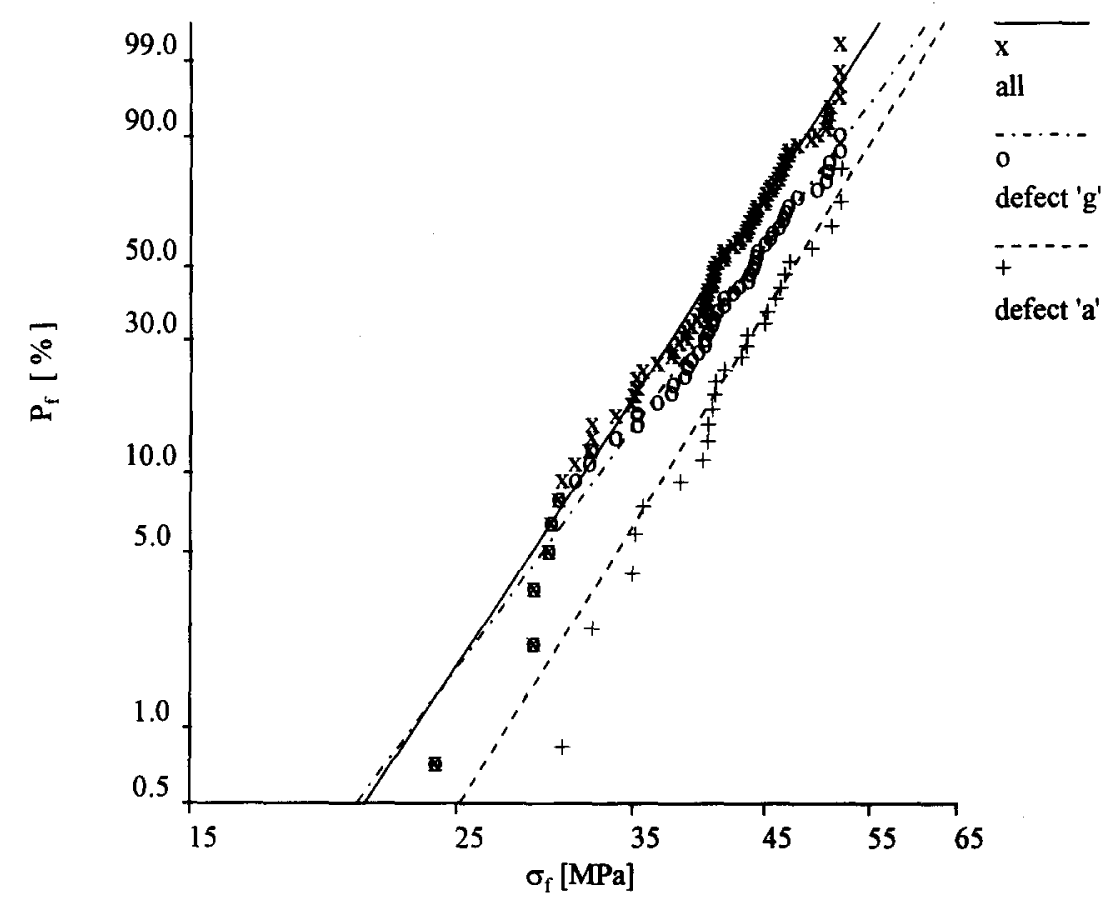

Fig. 7. Weibull plot of a complete test of type A cores, and the same set censored on failure on defects of type ' $\mathrm{g}$ ' and cores failed on defects of type ' $a$ '. 
defect types. As shown in Fig. 9, the stress rate still influences the actual strength in dry tests. Over the measured range of stress rate, a $17 \%$ strength reduction was found. The effect on strength of the presence of water is remarkably small, as compared

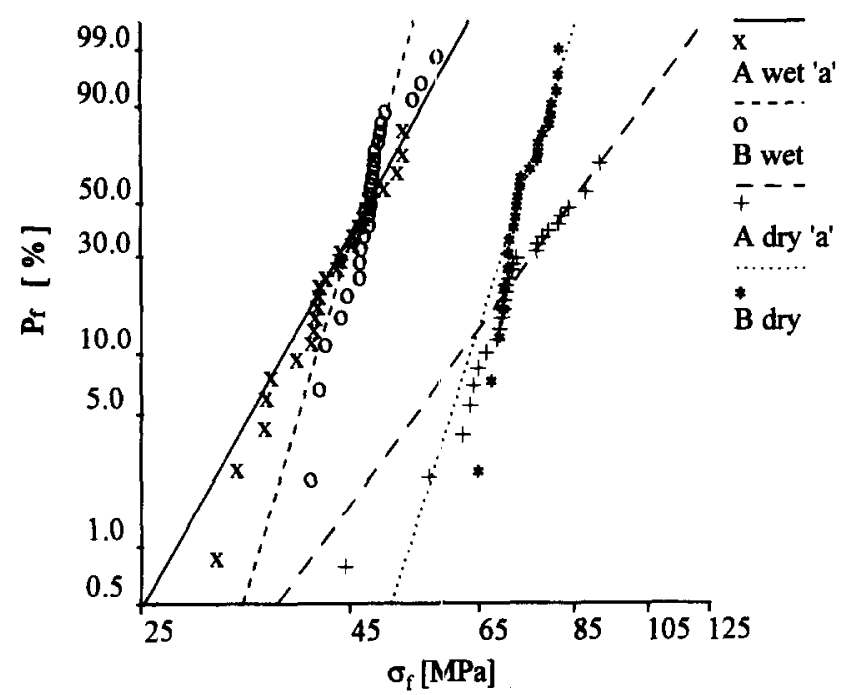

Fig. 8. Weibull plot of type $A$ cores censored to remove defect type ' $g$ ' and of type $B$ cores (defect type ' $g$ ' removed by adapted processing), both core types tested wet and dry.

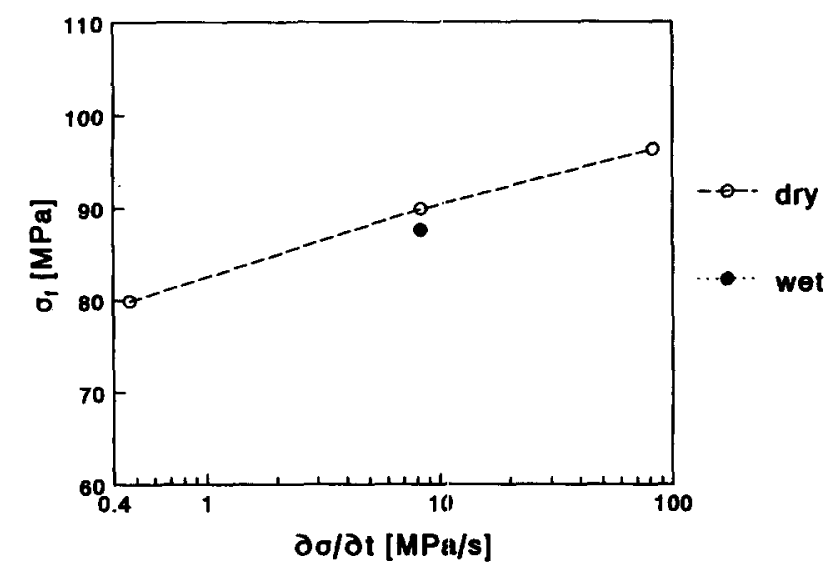

Fig. 9. Mechanical strength of ground cores (type ' $\mathrm{C}$ ') versus stress rate (normal markers indicate dry tests, bold markers indicate wet tests).

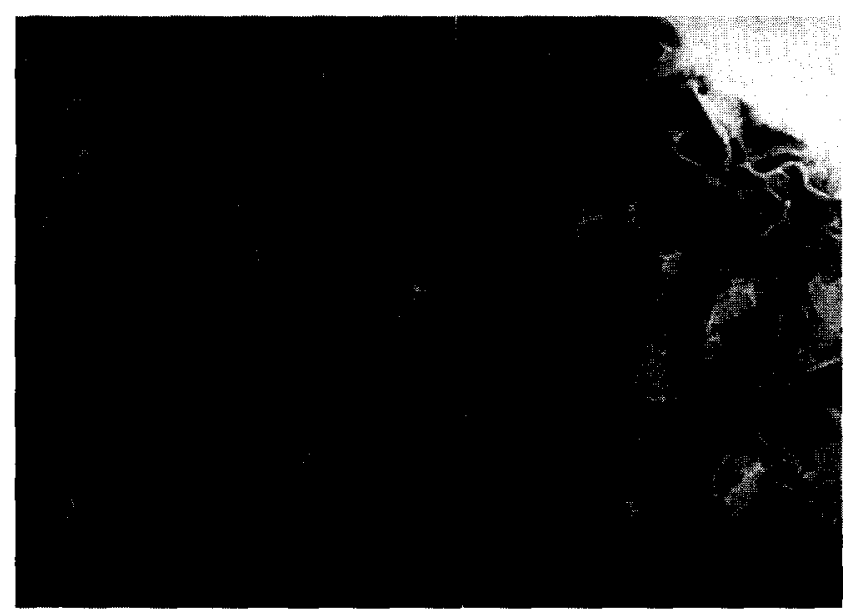

Fig. 10. Typical defect as found on the back of ground cores; SEM photograph, white bar indicates $10 \mu \mathrm{m}$, view on fracture surface with the tensile surface in upper right corner. with the unground cores. Fractographical analysis of the fracture surfaces showed that indeed no failure occurred on defects of type ' $a$ ' or ' $g$ '. Instead, small cracks, damage presumably caused by grinding and pores, act as critical defects (Fig. 10).

\section{Conclusions}

Constant stress rate strength measurements in dry and wet environments on $\mathrm{MnZn}$ ferrite cores have shown that this material is susceptible to subcritical crack growth. A clearly confirmed example of a concurrent flaw distribution is given by systematically employing fracture statistics and fractography. In this case, cores failing on one type of defect (excessively large grains) are shown to be more susceptible to SCG than those failing on the other type (pores surrounding agglomerates). Therefore the occurrence of failures on these defects changes with changing stress rate or humidity. Cores made with an adapted processing to prevent the formation of the large grains show a strength distribution comparable to that of the original cores having failed on the other defect type. Grinding $0.2 \mathrm{~mm}$ off the back of the cores removes both defect types, improves the mechanical strength and reduces the SCG susceptibility.

\section{References}

1. Dortmans, L. J. M. G. et al., Mechanical reliability of ferrite cores: Thermomechanical stress in operating conditions and in strength tests. In Proceedings Electroceramics $I V$, ed. R. Waser et al. Augustinus Buchhandlung, Aachen, Germany, 1994, pp. 1217-1218.

2. Huisman, D., Graaf, M. de and Dortmans, L., Thermomechanical stresses in a planar $E$ core during reflow soldering; a finite element based tool for reliability analysis. In Proceedings PCIM Conference, Nurnberg, 1995, pp. 593-596.

3. Johnson, D., Relationship between processing conditions, oxygen stoichiometry and strength of $\mathrm{MnZn}$ ferrites. In Processing of Crystalline Ceramics; Proceedings of the Fourteenth University Conference on Ceramic Science; Materials Science Research, Volume 11, ed. H. Palmour, R. F. Davis and T. M. Hare. Plenum Press, New York, 1977, pp. 381-391.

4. Greenberg Kosinski, S., Vaidya, S. and Johnson, D., Oxygen stoichiometry effects on the fracture of manganese zinc ferrites. Am. Ceram. Soc. Bull., 1978, 58, 616.

5. Johnson, D. W., Vogel, E. M. and Ghate, B. B., Recent progress on mechanical properties of ferrites. In Ferrites, Proceedings of the International Conference, ICF 3, Japan, 1980, pp. 285-291.

6. Neijts, R. C. and Dawson, W. M., The dependence of strength on composition and processing in $\mathrm{MnZn}$ ferrites. In Advances in Ferrites, Proceedings of the Fifth International Conference on Ferrites, ed. C. M. Srivastava and M. J. Patni. Oxford \& IBH Publishing, New Delhi, 1981, Vol. 1, pp. 293-297.

7. Lessof, H., Effect of moisture on strength of ferrite memory cores. J. Am. Ceram. Soc., 1971, 54, 353. 
8. Beauchamp, E. and Monroe, S. L., Effect of crackinterface bridging on subcritical crack growth in ferrites. J. Am. Ceram. Soc., 1989, 72, 1179-1184.

9. Kadouch, O., Lambelin, J. P. and Ansart, J. P., Time dependent statistical prediction models for ferritc $\mathrm{MnZn}$ ceramics. In Ferrites: Proceedings of The Sixth International Conference on Ferrites (ICF 6). The Japan Society of Powder and Powder Metallurgy, Tokyo, 1992, pp. 839-842.

10. Lawn, B., Fracture of Brittle Solids. Cambridge University Press, Cambridge, 1993.

11. Munz, D. and Fett, T., Mechanisches Verhalten keramischer Werkstoffe. Springer Verlag, Berlin, 1989.

12. Charles, R. J., Static fatigue of glass II. J. Appl. Phys., 1958, 29, 1554-1560.

13. Weibull, W., The phenomenon of rupture in solids. Royal Swedish Academy of Engineering Science Proceedings, 1939, 153, 1-55.

14. Johnson, L. G., The Statistical Treatment of Fatigue Experiments. Elsevier, Amsterdam, 1964.

15. Johnson, C. A., Fracture statistics of multiple flaw distributions. In Fracture Mechanics of Ceramics, Vol. 3 , ed. R. C. Bradt, D. P. H. Hasselman and F. F. Lange. Plenum Press, London, 1978, pp. 365-386.

16. Sainamthip, P. and Amarakoon, V. R. W., Role of zinc volatilization on the microstructure development of manganese zinc ferrites. J. Am. Ceram. Soc., 1988, 71, 644-648.

17. Okazaki, Y., Kitano, Y. and Narutani, T., Interaction between $\mathrm{Mn}-\mathrm{Zn}$ ferrite and $\mathrm{Al}_{2} \mathrm{O}_{3}$ refractory during sintering. In Ferrites: Proceedings of The Sixth International Conference on Ferrites (ICF 6). The Japan Society of Powder and Powder Metallurgy, Tokyo, 1992, pp. 313-316.

18. Rice, R. W., Processing induced sources of mechanical failure in ceramics. In Processing of Crystalline Ceramics; Proceedings of the Fourteenth University Conference on Ceramic Science; Materials Science Research Volume 11, ed. H. Palmour, R. F. Davis and T. M. Hare. Plenum Press, New York, 1977, pp. 303-319.

19. Ovri, J. E. and Davies, T. J., Uniaxial and biaxial strength of a sintered ferrite. In Science of Ceramics 14, ed. D. Taylor. Inst. Ceramics, Stoke-on-Trent, 1988, pp. 599605 